NBER WORKING PAPER SERIES

\title{
ENTER AT YOUR OWN RISK: \\ HMO PARTICIPATION AND ENROLLMENT \\ IN THE MEDICARE RISK MARKET
}

\author{
Jean Abraham \\ Ashish Arora \\ Martin Gaynor \\ Douglas Wholey \\ Working Paper 7385 \\ http://www.nber.org/papers/w7385

\section{NATIONAL BUREAU OF ECONOMIC RESEARCH 1050 Massachusetts Avenue \\ Cambridge, MA 02138 \\ October 1999}

The views expressed herein are those of the authors and not necessarily those of the National Bureau of Economic Research.

(C) 1999 by Jean Abraham, Ashish Arora, Martin Gaynor, and Douglas Wholey. All rights reserved. Short sections of text, not to exceed two paragraphs, may be quoted without explicit permission provided that full credit, including notice, is given to the source. 
Enter at Your Own Risk: HMO Participation and Enrollment in the Medicare Risk Market Jean Abraham, Ashish Arora, Martin Gaynor, and Douglas Wholey

NBER Working Paper No. 7385

October 1999

JEL No. I1, L1, I18

\section{ABSTRACT}

We examine HMO participation and enrollment in the Medicare risk market for the years 1990 to 1995 . We develop a profit-maximization model of HMO behavior, which explicitly considers potential linkages between an HMO's production decision in the commercial enrollee market and its participation and production decisions in the Medicare risk market. Our results suggest that the payment rate is a primary determinant of HMO participation, while the price of a supplemental Medicare insurance policy positively affects HMO Medicare enrollment. We also find empirical support for the existence of complementarities in the joint production of an HMO's commercial and Medicare products.

Jean Abraham

H. John Heinz III School of Public

Policy and Management

Carnegie Mellon University

Pittsburgh, PA 15213-3890

abraham@andrew.cmu.edu

Martin Gaynor

H. John Heinz III School of Public

Policy and Management

Carnegie Mellon University

Pittsburgh, PA 15213-3890

and NBER

mgaynor@andrew.cmu.edu
Ashish Arora

H. John Heinz III School of Public

Policy and Management

Carnegie Mellon University

Pittsburgh, PA 15213-3890

ashish@andrew.cmu.edu

\section{Douglas Wholey}

University of Minnesota

Division of Health Services Research

School of Public Health

15-223 Phillips-Wangensteen Building

Box 729, 420 Delaware Street SE

Minneapolis, MN 55455-0392

whole001@tc.umn.edu 


\section{Introduction}

Medicare is the federal entitlement program that provides comprehensive health insurance coverage to individuals age 65 and older and certain disabled people. In 1995, total Medicare expenditures reached $\$ 187$ billion dollars, with expected annual growth of ten percent (Statistical Abstract of the United States, 1997; Wilensky, 1995). With passage of the Balanced Budget Act of 1997, reforms are being implemented to address the program's financial condition and to expand beneficiary coverage options with the creation of Medicare Part C, otherwise known as Medicare+Choice.

Under Medicare+Choice, several types of coordinated care plans are eligible to contract with the Health Care Financing Administration (HCFA) to provide coverage to Medicare beneficiaries. ${ }^{1}$ This expands and modifies the Medicare HMO risk-contracting program begun in 1985. Under this program, an HMO entering into a "risk contract" receives a fixed monthly payment equal to $95 \%$ of an actuarial measure of the average cost of providing care to a beneficiary in the traditional Medicare program adjusted for geographic and demographic differences. This is called the Adjusted Average Per Capita Cost, or AAPCC. In return, the HMO is responsible for providing all covered services and takes full financial responsibility for the actual costs generated. ${ }^{2}$

In addition to expanding the types of organizations eligible to enter contracts, Medicare+Choice also differs from the preceding system with respect to the payment methodology. Though organizations participating in Medicare+Choice still receive a

\footnotetext{
${ }^{1}$ Medicare+Choice also permits fee-for-service insurers and religious fraternal benefit society plans to contract with HCFA.

${ }^{2}$ Additional regulations capped net revenues for risk-contracting HMOs. If an HMO exceeded the limit, then the firm would be required to take a lower payment rate or pass the savings onto the beneficiaries in the form of supplementary benefits or lower out-of-pocket costs. Premium rebates were prohibited. See (Zarabozo and LeMasurier, 1996) for discussion of TEFRA guidelines.
} 
fixed monthly payment to provide coverage for Medicare beneficiaries and bear the financial risk associated with the costs of providing care, a different methodology has been adopted for calculating this payment. Under Medicare+Choice, an organization's payment is based on the largest of three rates, which include the following: a minimum payment amount (which for 1998 is $\$ 367$ per month); a blended rate, which consists of the area-specific rate and an input-price adjusted national rate; and a minimum percentage increase which uses the AAPCC rate in 1997 as the base (www.hcfa.gov, 1998).

There has been considerable growth in recent years in both the number of HMOs offering Medicare products and HMO Medicare beneficiary enrollment. Table 1 summarizes HMO participation in the Medicare risk market for the years 1990 to $1995 .^{3}$ During this period, the number of HMOs participating in Medicare risk contracting nearly doubled, from 66 to 114 . As HCFA makes the transition into Medicare+Choice, effective implementation of this program depends on participation by coordinated care organizations, enrollment by beneficiaries, and a payment methodology that yields savings to Medicare that would not be realized under the traditional program.

The purpose of this paper is to directly examine two of these implementation issues: the decision by organizations to participate in the Medicare market and the factors that influence the number of beneficiaries who enroll in these institutions. Given the infancy of the Medicare+Choice program, we focus our analysis on HMO participation and enrollment decision-making as a way to identify insights that may apply more broadly to contracting organizations under this new program. 
Two studies have examined HMO entry into the Medicare market. Adamache and Rossiter (1986) examine the determinants of HMO participation in the National Medicare Competition demonstration, modeling this decision as a function of an HMO's organizational, market, and performance characteristics, and then estimating a binary probit model. ${ }^{4}$ Their results suggest that the AAPCC rate, federal qualification by an HMO, and prior experience with Medicare beneficiaries positively affect an HMO's probability of participation. Porell and Wallack (1990) model the problem similarly, using a different market definition and data set. The authors' findings confirm previous results, with additional results suggesting that stronger utilization controls and favorable financial performance by an HMO also increase the probability of entry into the Medicare market. However, both of these studies fail to directly address HMO production in the commercial enrollee market and how this may affect a firm's decision regarding Medicare, given the potential for important cost or demand linkages between these products. Furthermore, they also fail to consider the impact of what has become an important part of conventional Medicare - the price of supplemental Medicare insurance.

In this paper, we develop a model of HMO behavior that explicitly considers the linkage between an HMO's production in the commercial enrollee market and its decision to participate and produce in the Medicare market. We estimate the model using data from 1990 to 1995, which reflects a time period of significant growth and change in the HMO industry. The remainder of this paper is divided into the following sections. Section II presents the model. A discussion of the data and measures are

\footnotetext{
${ }^{3}$ Table 1 was constructed using data from a national sample of HMOs in the United States. Therefore, the number of risk-contracting HMOs reported in Table 1 is smaller than the number reported by HCFA for this time period.
} 
contained in Section III. Section IV outlines a set econometric estimation issues. Section V reports the results and provides a discussion of the findings. Section VI identifies potential policy implications and contains concluding remarks.

\section{Model}

In this section, we develop a profit-maximization model of HMO behavior. The primary objective for doing so is to examine how the Medicare price (the AAPCC payment rate), the price of substitutes for an HMO Medicare product (specifically the price of a supplemental Medicare insurance policy), and a firm's production in its private (commercial enrollee) market, influence its decision-making with respect to the Medicare market.

We employ the following set of assumptions. First, we consider the populations demanding each of these products to be separate, since only Medicare beneficiaries are eligible to enroll in a Medicare product, while most commercial enrollees are labor force participants and their families. Second, we assume that the products are distinguishable from one another by the fact that coverage under the traditional Medicare program and hence, Medicare products, is typically broader than that required for private products produced by federally qualified HMOs (Zarabozo and LeMasurier, 1996). Third, we assume that all HMOs produce a positive quantity of the private product. Finally, we allow for the possibility of demand complementarities for a firm's private and Medicare products.

\footnotetext{
${ }^{4}$ The National Medicare Competition demonstration occurred in 1982, and included 52 risk-contracting plans. See Langwell and Hadley (1982) and Langwell and Hadley (1986) for discussion.
} 


\section{Private demand}

Let an HMO face a separate demand function for each of its products, and let an HMO's demand function for its private product be specified as the following:

$Q_{p}=\theta_{0}-\theta_{1} P_{p}+\theta_{2} X_{p}+\theta_{3} Q_{m}, \theta_{i} \geq 0 \forall i$

where the private quantity $\left(\mathrm{Q}_{\mathrm{p}}\right)$ depends on the price charged for the private product $\left(P_{p}\right)$, $\mathrm{X}_{\mathrm{p}}$, which represents a set of exogenous factors that shift demand for the private product, and the firm's Medicare enrollment $\left(\mathrm{Q}_{\mathrm{m}}\right)^{5}$

\section{Medicare demand}

We specify the "potential" market demand for an HMO's Medicare product to be some function of the demographic composition of the Medicare population, a set of exogenous factors that shift HMO Medicare market demand $\left(\mathrm{X}_{\mathrm{m}}\right)$, and commercial enrollment. Individual firm demand is some proportion of this "potential" or residual market demand $\left(Q_{m R}\right)$, such that:

$Q_{m} \leq Q_{m R}$.

We specify individual firm demand as the following:

$Q_{m}=m_{1} z+m_{2} X_{m}+m_{3} Q_{p}$

where $\mathrm{z}$ represents the quality level of the Medicare product chosen by the firm, $\mathrm{X}_{\mathrm{m}}$ is a vector of exogenous factors that shift HMO Medicare market demand (such as the price of supplemental Medicare insurance), and $\mathrm{Q}_{\mathrm{p}}$ is a firm's private quantity. ${ }^{6} \mathrm{We}$ assume

\footnotetext{
${ }^{5}$ This specification does not explicitly model strategic interaction by firms in the private market. Assume this represents a reduced form residual demand curve with $\gamma$ capturing factors that shift rivals' demands as well as the firm's own demand.

${ }^{6}$ This specification also does not explicitly model strategic interaction among firms in the Medicare market. It subsumes rivals' actions and should be considered a reduced form specification. We assume
} 
that $\mathrm{Q}_{\mathrm{m}}$ is not directly under the control of the firm, but rather is influenced by the quality of the product $(\mathrm{z})$, which is set by the firm.

\section{Medicare price}

In contrast to the private market, the Medicare price is set administratively by the Health Care Financing Administration, rather than being determined as a function of quantity. Under federal guidelines, the price of the Medicare product $\left(P_{m}\right)$ is set equal to $95 \%$ of the AAPCC, which is an actuarial measure of the average cost of providing care to a beneficiary enrolled in the traditional Medicare program, adjusted for age, sex, geographic, Medicaid eligibility, and institutional status differences.

\section{Costs}

The firm faces the following cost function associated with its production of the private and Medicare products::

$$
C=C_{1} Q_{m}+C_{2} Q_{p}+C_{3} Q_{p} Q_{m}+C_{4} Q_{m}^{2}+C_{5} Q_{p}^{2}+C_{6} z Q_{m}+C_{7} z+C_{8} z^{2}
$$

Total cost is a function of the private and Medicare quantities and the quality level chosen by the firm. The third cost parameter, $C_{3}$, captures those costs associated with the joint production of the private and Medicare products.

The last two terms in the cost function specification capture the fixed cost associated with production of a Medicare product, where this cost is strictly increasing with the level of quality chosen by the firm. HMOs may incur fixed costs for such things as new equipment purchases, facility renovation for easier accessibility by the 
elderly, development of geriatric programs, marketing, or administrative services related to the risk contract application process and compliance with government regulation.

\section{Entry Decision}

Based on the above assumptions, the decision for an $\mathrm{HMO}$ to enter the Medicare market is a function of the variable profit and fixed cost associated with production of a Medicare product. Entry by the firm will occur when, for a given level of quality, the following condition holds:

$$
\left(P_{m}-C_{1}-C_{3} Q_{p}-2 C_{4} Q_{m}-C_{6} z\right) Q_{m}-\left(C_{7} z+C_{8} z^{2}\right) \geq 0 .
$$

Using this condition, we can assess how changes in the price, costs, or private enrollment affect a firm's probability of entry into the Medicare market. For example, if the Medicare price increases, this increases a firm's variable profit, and will increase its likelihood of participation. Second, if variable or fixed costs increase, this will decrease the probability of entry by the firm, ceteris paribus. Finally, the probability of participation depends on the presence of complementarities. If there are demand or cost complementarities, then an increase in a firm's private enrollment $\left(\mathrm{Q}_{\mathrm{p}}\right)$, will serve to increase its probability of participation in the Medicare market.

To examine how these factors affect a firm's probability of entry into the Medicare market, we construct a binary dependent variable, OFFER, defined as the following:

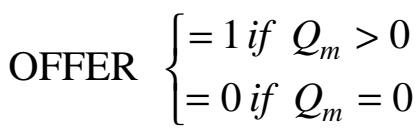

and designate the model as the following:

$\operatorname{Prob}($ OFFER $=1)=\beta_{1}+\beta_{2} P_{m}+X_{m} \beta_{3}+X_{p} \beta_{4}+($ COST $) \beta_{5}$ 
where the decision to offer a Medicare product is a function of a constant, the Medicare

price, Medicare demand shifters, private demand shifters, and factors that shift an

HMO's costs (COST). This equation is a reduced form specification derived

from the preceding entry condition.

\section{Profit-Maximization Problem}

We assume that HMOs seek to maximize profits. ${ }^{7}$ The firm's problem is then:

$\operatorname{Max} \pi=P_{p} Q_{p}+P_{m} Q_{m}-C_{1} Q_{m}-C_{2} Q_{p}-C_{3} Q_{p} Q_{m}-C_{4} Q_{m}{ }^{2}-C_{5} Q_{p}{ }^{2}-C_{6} z Q_{m}-C_{7} z-C_{8} z^{2}$

Qp, z

subject to:

(1) $Q_{m} \geq 0$

(2) $Q_{p}-Q_{m} \geq 0$

(3) $Q_{m R}-Q_{m} \geq 0$

where an HMO chooses its private quantity and level of quality to maximize profit subject to the three constraints. Constraint (1) reflects an HMO's choice to participate in the Medicare market. Constraint (2) reflects federal guidelines that require HMOs not to have more than $50 \%$ of their total enrollment from Medicare enrollees. Constraint (3) requires that no individual firm's demand for its Medicare product exceed its residual market demand. ${ }^{8}$

Table 2 outlines four possible cases of HMO behavior under various combinations of slack and binding constraints. Case I includes all HMOs that have

\footnotetext{
${ }^{7}$ Profit-maximization is the appropriate assumption, even for non-profit HMOs, provided that the HMO seeks to maximize the income of a decisive set of agents, or that the residual claimants can agree on maximizing their joint gain (Pauly, 1987; Danzon, 1982). A separate model for non-profit HMOs is required only if something which affects demand (e.g., output) also appears in the HMO's objective function. Since this is uncertain, we do not believe there is a need for a special model of non-profit HMOs (Wholey et al, 1995). In our data set, approximately $70 \%$ of HMOs have for-profit status.

${ }^{8}$ See Appendix 1 for the first-order and second-order conditions of the profit-maximization problem.
} 
chosen to operate in the private market only. HMOs that fall into Case II participate in both the private and Medicare markets, and are constrained by the 50/50 rule. Case III includes HMOs that participate in both markets and that are constrained by demand in the Medicare market. This suggests that an individual firm's demand equals its residual market demand, and therefore, no further increases in quality can increase firm demand. Finally, Case IV includes those HMOs that operate in both markets and are neither constrained by the 50/50 rule, nor constrained by demand. Cases I, III, and IV appear to be the most empirically plausible. Descriptive statistics from the data reveal that less than two percent of all operational HMOs are constrained by the 50/50 rule, and therefore, fall into Case II.

To examine the determinants of an HMO's private and Medicare enrollment, we use the first order conditions of the profit-maximization problem to specify the enrollment equations below. Specifically, we solve for $Q_{p}$ and $Q_{m}$ individually from first order conditions (1) and (2), and impose an assumption of linearity. These single equation, implicit solutions are expressed as the following:

$$
\begin{aligned}
& Q_{m}=\alpha_{1}+\alpha_{2} P_{m}+X_{m} \alpha_{3}+(\operatorname{COST}) \alpha_{4}+\alpha_{5} Q_{p} \\
& Q_{p}=\omega_{1}+\omega_{2} P_{m}+X_{p} \omega_{3}+(\operatorname{COST}) \omega_{4}+\omega_{5} Q_{m} .
\end{aligned}
$$

Here, an HMO's Medicare quantity is a function of the Medicare price, Medicare demand shifters, factors that shift cost, and private quantity, while a firm's private quantity is a function of the Medicare price, private demand shifters, factors that shift cost, and a firm's Medicare quantity.

Appendix 2 outlines a set of comparative static predictions that are used to assess how changes in the Medicare price and factors that shift private and Medicare demand 
affect an HMO's behavior regarding private and Medicare enrollment. Using our predictions, we can distinguish between Case III (firms are demand constrained) and Case IV (firms are unconstrained), and utilize this information in relating our empirical results back to theory. Furthermore, we use combinations of predictions to test for the presence of complementarities in production.

Table 3 reports these predictions, where the parameters identified are those specified in equations (8) and (9). We can distinguish between the demand constrained and unconstrained cases using the parameter on the Medicare price in the Medicare quantity equation. Finding a zero effect suggests that the firm is demand constrained, while finding a positive effect, suggests that the firm responds to an increase in price and is therefore, unconstrained by demand. To test for complementarities, we use the signs on the parameter estimates for $\mathrm{Qp}, \mathrm{Qm}$, and Pm in the Medicare and private enrollment regressions, respectively. Finding a positive effect suggests the presence of complementarities.

\section{Empirical Specification}

\section{Data}

We used the InterStudy HMO Census to identify the population of HMOs in the United States from 1990 to 1995 . The InterStudy Census describes the organizational structure of HMOs in terms of model type, profit status, headquarters location, and federal qualification. In addition, the Census indicates changes in ownership (organizational name changes, mergers) and plan terminations.

We matched the InterStudy data with information obtained from forms that HMOs file with state regulators. The state filings include financial information, 
enrollment figures, and utilization statistics. We obtained these from Health Care Investment Analysts (HCIA), who code the data, and sell them in machine readable format. We matched 2564 (80.2\%) of the 3197 HMOs identified in the InterStudy Census with HMOs in the HCIA data. Matches did not occur for a variety of reasons: financial forms were not available from some states (ie: Hawaii); some national firms filed the same statement in all states in which they operated; and some forms were missing for unknown reasons. We were more likely to have data for independent practice association (IPA) HMOs than non-IPA HMOs, for federally-qualified HMOs, and for firms affiliated with a national HMO. We were less likely to have data for HMOs affiliated with a non-HMO based national firm (ie: insurer) and for firms associated with Blue Cross Blue Shield. Fifty-two observations for which private enrollment was identified as being zero were excluded from the final empirical analysis.

County-level data from the Area Resource File were used to construct demographic and economic market measures. The Health Care Financing Administration was the source for data on the Adjusted Average Per Capita Cost, and data on supplemental Medicare insurance policy premiums were obtained from a report issued by the Families USA Foundation and supplemented through direct correspondence with the American Association of Retired Persons.

\section{Unit of Analysis}

The HMO is the unit of analysis for this study. HMOs frequently operate in multiple geographic markets and so HMO market measures were developed through a process consisting of several steps. In the first step, the counties in which the HMO 
operates were obtained from InterStudy Censuses (1990 to 1995). Second, in a recent InterStudy survey, HMOs were asked to list enrollment by Metropolitan Statistical Area (MSA). We were able to allocate enrollments to MSAs and use county population weights to allocate enrollment within MSAs that span over more than one county. Residual enrollment not included in these MSAs was allocated over the counties served by the HMO that are not in MSA counties where the HMO allocated enrollment. In the third step, market characteristics (e.g., input prices) were created for each HMO, using a weighted average of the county-level variables over all counties where the HMO operates. Weights were calculated as the HMO's estimated enrollment in a county divided by its total enrollment over all counties it serves. For example, if an HMO operates in two counties with enrollments of 10,000 and 30,000, and the average nurse wage rate is $\$ 12$ and $\$ 16$ respectively, then the nurse wage rate for the HMO market is $[(1 / 4) * 12+(3 / 4) * 16]=\$ 15($ Wholey et al, 1995).

\section{Variables}

As stated in the theoretical section, firms choose the quantity of the private product and level of quality for the Medicare product in order to maximize profits. While we do not have any empirical measures for quality, a firm's quantity of Medicare enrollees is a function of quality, and is observable. The product that an HMO produces is defined as a member month of health care coverage, with the private and Medicare quantities denoted as $\mathrm{Q}_{\mathrm{p}}$ and $\mathrm{Q}_{\mathrm{m}}$, respectively. We use the AAPCC county base rate for the aged as our measure of the Medicare price.

Factors affecting Medicare demand $(\boldsymbol{\delta})$ : 
We control for differences in the demographic composition of markets by including the proportion of the population 65 to 74 years of age and the proportion 75 years of age and older. Approximately $70 \%$ of beneficiaries purchase supplemental Medicare (Medigap) insurance to cover services not included in the traditional Medicare benefits package, as well as out-of-pocket costs, such as co-insurance and deductibles (Zarabozo and LeMasurier, 1995). An HMO Medicare product frequently includes a set of benefits that are comparable to a combination of traditional Medicare and a supplemental Medicare policy. In markets where Medigap premiums are high, an HMO Medicare product may be perceived as an attractive substitute. In 1992, supplemental Medicare insurers were required by federal law to limit their selection of policies to ten standardized packages (National Association of Insurance Commissioners, 1996). We use annual premiums for AARP/Prudential supplemental Medicare insurance (Package A) to proxy for the price of a supplemental Medicare policy (Dallek, 1996; Smolka, 1996). ${ }^{9,10}$ To deal with missing premium data, we construct an indicator variable that takes on a value of one if the premium data is missing and sets the Medigap premium to zero. $^{11}$

Factors affecting private demand $(\gamma)$ :

\footnotetext{
9 Package A includes coverage for the Medicare Part A coinsurance amount for the 61st-90th day of hospitalization; coverage for the Part A coinsurance amount for each of the 60 non-renewable lifetime hospital inpatient reserve days; coverage for $100 \%$ of the Medicare Part A eligible hospital expenses; coverage for three pints of blood; and coverage for the coinsurance amount for Part B services after the $\$ 100$ deductible has been met (National Association of Insurance Commissioners, 1996).

${ }^{10}$ AARP/Prudential uses a community rating method to calculate premiums, which means that it does not charge differentiated prices based on age, health status, or geographic location within a state. We acknowledge that endogeneity issues may be present if HMOs in the market experience favorable selection, leading to a costlier traditional Medicare population on which supplemental Medicare insurance premiums are calculated.

${ }^{11}$ See Greene (1993) for a discussion of this technique. Most of the missing premium data come from Massachusetts, Minnesota, and Wisconsin, which all received waivers for alternative simplification plans prior to 1990.
} 
To capture the effect of income on private demand, we use the percentage of families below the poverty level. If the freedom to choose one's physician in the fee-forservice sector is a normal good, then there should be a positive relationship between poverty and demand for an HMO's private product. Second, we include the annual rate of change in the population under 65 years of age to proxy for the migration of younger persons into market areas served by HMOs. Third, we include the proportion of the population, 25 years of age and older, that has obtained at least a four-year college degree. Fourth, we include the proportion of active physicians in the market who are pediatricians, which should proxy for the prevalence of pediatric services provided in a market. Here, we assume that pediatricians' services are an input to the production of coverage for the private population only. ${ }^{12}$ Finally, we include a set of indicator variables pertaining to the state regulatory environment for HMOs. These measures cover such issues as whether subscribers have a policy-making role, whether employers are required to offer an HMO option for their employees' health coverage, whether HMO rates must have state approval, and whether HMOs are required to have an open enrollment period. ${ }^{13}$

\section{Factors affecting HMO cost structure (COST):}

While we do not observe empirical measures to differentiate among the cost parameters, we do employ a set of measures to capture various input prices. Nurse and administrative wage rates from the fee-for-service sector will be used to measure labor costs, based on the assumption that these measures are highly correlated with an HMO's

\footnotetext{
${ }^{12}$ Note that while we considered including measures of HMO competition and market penetration for the private enrollee population, we chose not to because of endogeneity issues.

${ }^{13}$ To deal with missing regulations data, we again adopt the indicator variable technique discussed in Greene (1993).
} 
corresponding labor costs. Hospital inpatient price per diem and the price of an office visit of intermediate complexity are both measures from the fee-for-service sector which should also be highly correlated with input prices faced by HMOs. To control for differences in health status across markets, we use an average infant mortality measure. We expect that in markets where the population is less healthy, there will be higher utilization of services, resulting in higher costs to an HMO. Finally, federal qualification may be considered to lower an HMO's fixed cost of offering a Medicare product, since those HMOs that are federally qualified have already incurred some of the administrative costs associated with entering a risk contract. HMO characteristics affecting both demand and costs:

An HMO's age may be an indicator of the acceptance of the HMO concept in a market. Also, over time, HMOs may gain experience and organizational knowledge in the provision of care, leading to more efficient production. Ownership (for-profit or nonprofit status) may also affect both demand and cost. Debate continues regarding the role of for-profit organizations in health care, with some considering profit-seeking behavior as inappropriate for this industry (Hansmann, 1987). With regard to costs, it is plausible that the profit motivation may lead managers of for-profit institutions to place greater emphasis on cost minimization in production. However, an alternative demand-side argument suggests that individuals frequently associate not-for-profit HMOs with higher quality of care, and thus may be more likely to enroll in a not-for-profit, than a for-profit HMO (Wholey et al, 1995). Additionally, HMO model type may suggest differing production technologies, leading to differing abilities to contain costs. The relationship between model type and an HMO's physician panel may also influence demand. A set of 
dummy variables are included to control for HMO model type (staff, group, network, and mixed, with IPA as the excluded variable) (Wholey et al, 1996). We also include indicator variables for whether a firm is affiliated with a national HMO, a national insurer that is not an HMO, or Blue Cross Blue Shield. Affiliations with these institutions may affect a firm's access to capital and organizing expertise, which may in turn, affect its production decision. Finally, we include a set of dummy variables for each year in our sample (1990 as the excluded variable) to capture time trends.

\section{Econometric Specification}

We estimate a two-part econometric model for this analysis. In the first part, we focus on an HMO's decision regarding its participation in the Medicare risk market. As discussed in Section II, the decision to offer a Medicare product is modeled as the following:

$\operatorname{Prob}($ OFFER $=1)=\beta_{1}+\beta_{2} P_{m}+X_{m} \beta_{3}+X_{p} \beta_{4}+($ COST $) \beta_{5}+\varepsilon_{1}$.

With repeated observations on the same set of cross-section units, we are concerned about the presence of unobserved HMO-specific effects. We estimate the participation regression as a probit within a generalized estimating equations framework, additionally using a Huber/White/sandwich estimator of variance that allows for within HMO group correlation and heteroscedasticity across HMOs. ${ }^{14}$ Table 6 reports the results for this regression.

The second part of the model focuses on the factors that determine HMO enrollment in both the Medicare and private products. The enrollment equations to be estimated are specified as:

\footnotetext{
${ }^{14}$ See Appendix 3 for additional discussion of econometric estimation methods.
} 


$$
\begin{aligned}
& Q_{m}=\alpha_{1}+\alpha_{2} P_{m}+X_{m} \alpha_{3}+(\text { COST }) \alpha_{4}+\alpha_{5} Q_{p}+\varepsilon_{2} \\
& Q_{p}=\omega_{1}+\omega_{2} P_{m}+X_{p} \omega_{3}+(\text { COST }) \omega_{4}+\omega_{5} Q_{m}+\omega_{6}(\text { OFFER })+\varepsilon_{3} .
\end{aligned}
$$

Equation (11) is estimated only for firms that participate in the Medicare market, while equation (12) is estimated for all firms in the sample. ${ }^{15,16}$

We encounter two estimation issues, which include the simultaneity of $Q_{p}$ and $Q_{m}$, and the presence of unobserved HMO-specific effects. Instrumental variables estimation is used to deal with the simultaneity of our enrollment measures. To instrument for an HMO's private enrollment, we use our private demand shifters. The rate of change in the population under 65 years of age reflects the potential growth of the market for an HMO's commercial product and should be exogenous with respect to a firm's Medicare enrollment. Second, we use the percentage of poor families, asserting that this measure reflects the income of the non-Medicare beneficiary population. The ratio of pediatricians to active medical doctors is also used, since this measure should reflect the potential market demand for pediatric services, which should be used predominantly by an HMO's commercial enrollees. Finally, indicator variables capturing an HMO's regulatory environment as well as the proportion of the population who have four or more years of college are also used as private enrollment instruments.

To instrument for an HMO's Medicare quantity, we use the AAPCC rate, supplemental Medicare insurance premiums, and our two demographic measures which capture the proportion of the population ages 65 to 74 and the proportion 75 years and

\footnotetext{
${ }^{15}$ We include both OFFER and the Medicare quantity in the private quantity equation because we consider the decision whether to offer and how much to offer to capture a joint outcome. In estimating the Medicare enrollment regression, we use the predicted value for OFFER.
} 
older. ${ }^{17,18}$ These factors should all serve to influence HMO Medicare enrollment, but not directly affect an HMO's commercial enrollment. To obtain consistent estimates of our standard errors, we again use the Huber/White/sandwich estimator of variance. ${ }^{19}$

By estimating this model as two separate parts, we have not considered the issue of selection, whereby HMOs choose whether or not to offer a Medicare product. In taking this approach, our inferences may be applicable to only those HMOs in the sample. Given the possibility of selection issues, we also adopt the conventional approach in the literature and estimate the Medicare enrollment regression with an inverse Mill's ratio measure (lambda), constructed using predicted values from the participation regression. ${ }^{20}$ Both specifications are reported in Table 7.

\section{Results and Discussion}

Tables 4 and 5 provide definitions and descriptive statistics of the measures used in this analysis. Missing values for 75 observations reduce the sample size to 2437 . We use all observations to estimate equations (1) and (3). For equation (2), we use only those observations which have positive Medicare enrollment $(\mathrm{N}=490)$.

\footnotetext{
${ }^{16}$ We also estimate the model using various transformations of the enrollment measures, including the natural $\log$ and the square-root of private and Medicare quantities. The results are qualitatively similar and the linear model was chosen based on fit.

17 One issue regarding the use of the AAPCC and Medigap variables as instruments is that that they reflect general health care costs and health status of the population in a market. It is unclear if expenditure growth patterns for the Medicare and private populations are the same. In fact, for the time period of the study, Medicare expenditures were growing significantly faster than private personal health care expenditures (HCFA Statistical Supplement, 1996). Nor is it clear that health status for the under 65 and Medicare eligible populations are highly correlated in a given market.

18 To examine the "quality" of our instruments, we separately ran regressions of our enrollment quantities on all predetermined variables in the system and then performed joint F-tests on the instruments. In both regressions, the instruments were jointly significant at the 1\% level. See Staiger and Stock, 1997. ${ }^{19}$ See Appendix 3 for an explanation of the Huber/White/sandwich variance estimator.

${ }^{20}$ We specify federal qualification of an HMO to affect the decision to offer a Medicare product, but not to affect enrollment. This specification enables identification to be based on something in addition to functional form assumptions.
} 
Table 6 reports our results from the participation regression, which are generally consistent with theoretical predictions. Most notably, we obtain a positive and significant coefficient on the AAPCC measure. In our sample, the average AAPCC payment rate is \$349. Using our estimates, we calculate the average impact of a $\$ 35$ increase in the AAPCC increases the probability that an HMO offers a Medicare product by $.028 .{ }^{21}$ Additionally, the elasticity of the probability of entry with respect to the AAPCC payment rate (evaluated at the mean) is equal to 1.39 , suggesting a large behavioral response by HMOs.

Finding this response suggests that the payment rate, which is set to reflect the predicted costs of providing coverage to beneficiaries, does a poor job of adjusting for differences in risk between beneficiaries in traditional Medicare and those who enroll in HMOs. Since the AAPCC rate is constructed to correspond to HMOs earning zero economic profits in the Medicare market, cross-sectional differences in its value should not be associated with differential entry. However, finding this effect indicates that areas with higher AAPCC rates are more profitable, and thus cost differences have not been accurately adjusted.

Second, the proportion of the population 65 to 74 years of age and 75 years and older, are statistically significant with positive and negative coefficient signs, respectively. This suggests that the demographic composition of the Medicare population affects an HMO's participation decision in a way that is consistent with favorable

\footnotetext{
${ }^{21}$ The average predicted probability for our sample is .198. We find the effect of the AAPCC on an HMO's probability of entry to be smaller in magnitude as compared with the findings of Adamache and Rossiter (1986) and Porell and Wallack (1990).
} 
selection. $^{22}$ We also find that as the rate of change in the under 65 population increases, which shifts demand for an HMO's private product, this decreases the probability of an HMO offering a Medicare product. Finally, HMOs that have federal qualification, affiliation with a national HMO organization, and are older are associated with an increased probability of Medicare market participation.

Table 7 reports our results from estimation of the enrollment regressions. ${ }^{23} \mathrm{We}$ find that the results for the Medicare enrollment regression do not change substantially when the selection correction is included, and that the estimate on the inverse Mill's ratio is statistically insignificant. In both the private and Medicare enrollment regressions the coefficients on the instrumented enrollment measures are positive and statistically significant, suggesting complementarities in the joint production of a firm's private and Medicare products. Given the particular model specification, we are unable to empirically distinguish between demand and cost complementarities. ${ }^{24}$

With respect to the AAPCC payment rate, we find that it has no significant effect on Medicare enrollment. Two possible interpretations suggest that either the coefficient estimate is so imprecisely estimated that we simply can't discern an effect or that the coefficient is truly zero, which is consistent with the demand constrained case. In contrast, we find a positive and significant effect of the price of a supplemental Medicare insurance policy on Medicare enrollment. This is consistent with the argument that as supplemental Medicare premiums increase, beneficiaries are likely to consider enrollment

\footnotetext{
${ }^{22}$ We are cautious in this assertion since this result may be partially due to the fact that the AAPCC payment measure used in this analysis is not specifically adjusted to reflect the actual demographic composition of enrollees that an HMO would face.

${ }^{23}$ The standard errors for the Medicare enrollment regression estimated with the selection correction term will not be exactly correct, since we are using a predicted value of lambda in the specification.
} 
in an $\mathrm{HMO}$ as a substitute for the combination of traditional Medicare and a supplemental policy.

Relating our empirical results back to our theory, we refer back to the predictions outlined in Table 3. First, we cautiously conclude that HMO behavior is consistent with the demand constrained case, given our insignificant effect on a change in the Medicare price on Medicare enrollment $\left(\alpha_{2}=0\right)$. Second, we find support for the presence of complementarities in production. We find positive and significant relationship between a firm's private and Medicare quantities in the enrollment regressions, which suggests either demand or cost complementarities $\left(\alpha_{5}>0, \omega_{5}=0\right)$. Additionally, we find a positive effect of the Medicare price on private quantity, however, because of the imprecision with which the coefficient is estimated, it provides only marginal support.

\section{Policy Implications}

Participation by coordinated care organizations, beneficiary enrollment, and a payment methodology that yields savings to Medicare, are three key implementation objectives for Medicare+Choice. Under this new program, the methodology used to calculate payments to contracting organizations has changed. In an effort to induce entry into the Medicare market, one modification in payment policy includes the establishment of a minimum payment level to organizations located in markets which historically have experienced low AAPCC payment rates.

To assess the effect of implementing such a policy, we compute a set of predicted probabilities of entry into the Medicare market for a subset of HMOs that reflect the characteristics of the target group affected by the minimum payment policy.

\footnotetext{
${ }^{24}$ The studies of Wholey et al (1996) and Given (1996), find the presence of diseconomies of scope in the joint production of private and Medicare products. This suggests our results may be due to demand
} 
Specifically, our subset consists of HMOs that do not offer a Medicare product and that have AAPCC payments less than the Medicare+Choice minimum payment level. ${ }^{25}$ Using our probit results, we compute a set of predicted probabilities of entry into the Medicare market for the minimum, median, and maximum payment rates associated with this group, with all other regressors held at the sample mean. These results are found in Table 8. While the predicted probabilities for this set of HMOs are low, ranging from .0785 to .1373 , increasing the payment rate from the minimum in the sample to the designated Medicare+Choice minimum payment rate increases the predicted probability of entry by almost $75 \%$.

Using the payment rate for the purpose of inducing entry raises two additional issues. First, adopting such a policy may lead to the payment of rents to incumbent HMOs who are already operating in markets for which the minimum payment rate applies. Second, there may be factors other than the payment rate which deter entry by firms. Such issues may include a scarcity of potential enrollees or lack of negotiating power with providers (Serrato et al, 1995). Given the low probability of entry, these results further suggest that some of the new alternatives under Medicare+Choice (e.g., medical savings accounts) may be more successful in these areas relative to HMOs, perhaps due to lower fixed costs of entry.

Rather than using the payment rate to induce entry, an alternative policy tool would be for the government to individually subsidize the sunk costs of entry for organizations operating in markets with little or no program participation. Without having estimated the parameters of the cost function, we are unable to directly calculate

complementarities. 
firms' sunk costs using the entry condition identified in Section II. However, using data from 1995, we calculate an approximation of the upper bound on sunk costs for entry into the Medicare market under three hypothesized profit rates. Since variable profits must exceed sunk costs for a firm to enter, an estimate of variable profits serves as an upper bound on sunk costs. We calculate variable profits as $\mathrm{P}_{\mathrm{m}} \cdot \mathrm{Q}_{\mathrm{m}} \cdot \phi$, where $\phi$ is equal to the profit per dollar of revenue. We simulate this for various values of $\phi$.

For this exercise, we subdivide the group of new entrants into three geographic regions (West, Central, and East), and select the firm with the largest Medicare enrollment in its first year of participation. Choosing the largest new entrant allows us to get an upper bound on the sunk costs in each of the regions, presuming that sunk costs are not decreasing in size. Table 9 reports the estimated sunk costs of entry for each firm under values of $\phi$ equal to $.05, .1$, and .2 and a calculation of the sunk cost per member month. With direct information on $\phi$, one could then compare the actual cost of using the payment rate per beneficiary as a method for inducing plan participation versus direct subsidization of sunk costs.

A final, broader policy implication stems from the complementarities result. Finding empirical support for the presence of demand and/or cost linkages across a firm's private and Medicare markets has important ramifications for policy design and evaluation. First, it suggests that federal policies for this program should take account of firms' private market activities when designing Medicare policy related to participation and enrollment. For example, in locations where there is significant growth in commercial enrollment, Medicare could decrease payment rates to contracting firms,

\footnotetext{
${ }^{25}$ We first deflated the 1998 minimum payment level of $\$ 367$ to 1995 dollars before selecting our subset of
} 
without inducing exit, if indeed there are complementarities which serve to partially offset the shock. Second, with respect to policy evaluation, if there are linkages between these markets, then it becomes increasingly difficult to isolate the effect of a policy intervention on Medicare market activity (e.g., growth in HMO Medicare enrollment) from changes that result simply due to a firm's commercial market activities.

\section{Concluding Remarks}

In this paper we have developed a model of HMO behavior to examine both participation in the Medicare market and HMO Medicare enrollment. We estimate a two part model using data from HMOs in the United States over the time period of 1990 to 1995, and obtain results that are generally consistent with our theoretical predictions. Three primary conclusions can be drawn from this research. First, we find evidence to support the assertion that changes in the payment rate may have direct implications for participation by firms in the Medicare market. While the specific payment methodology has been revised with the institution of Medicare+Choice, we believe that the effect of changes in payment will continue to have a significant effect on participation by coordinated care plans. Second, while enrollment by Medicare beneficiaries is dependent on plan participation, it is also a function of the set of insurance alternatives available to beneficiaries, such as the combination of traditional Medicare and supplemental insurance policies. By broadening the set of coverage choices available to beneficiaries, this may subsequently introduce additional issues for regulators with respect to competitive behavior by contracting plans. Third, we find empirical evidence in support of a linkage between a firm's private and Medicare products, giving rise to additional concerns regarding policy design and evaluation. As HCFA makes the 
transition and expands from its risk-contracting program to Medicare+Choice, it is worthwhile to recognize and integrate lessons learned under TEFRA, specifically regarding how payment rates and beneficiary options impact implementation strategies and design of future Medicare policy. 
Table 1: HMO Medicare market activity

\begin{tabular}{|l|l|l|l|l|}
\hline Year & Entry & Exit & Continuing & Total Offer \\
\hline 1990 & Not available & Not available & Not available & 66 \\
\hline 1991 & 15 & 20 & 46 & 61 \\
\hline 1992 & 32 & 10 & 51 & 83 \\
\hline 1993 & 12 & 18 & 65 & 77 \\
\hline 1994 & 34 & 14 & 63 & 97 \\
\hline 1995 & 25 & 8 & 89 & 114 \\
\hline
\end{tabular}

Table 2: Cases

\begin{tabular}{|l|l|l|}
\hline Case & Regime & HMO behavior \\
\hline I & $\lambda>0, \rho=0, \sigma=0$ & HMO does not participate in Medicare market \\
\hline II & $\lambda=0, \rho>0, \sigma=0$ & HMO participates in both markets and 50/50 constraint \\
& binds \\
\hline III & $\lambda=0, \rho=0, \sigma>0$ & HMO participates in both markets and is constrained by \\
\hline IV & $\lambda=0, \rho=0, \sigma=0$ & HMO participates in both markets and is unconstrained \\
\hline
\end{tabular}

Note: $\lambda, \rho, \sigma$ are Lagrange multipliers on constraints (1), (2), and (3), respectively, from the optimization problem.

Table 3: Predicted effects

\begin{tabular}{|l|c|c|c|c|}
\hline & $\begin{array}{c}\text { Demand } \\
\text { constrained } \\
\text { (Case III) }\end{array}$ & $\begin{array}{c}\text { Unconstrained } \\
\text { (Case IV) }\end{array}$ & $\begin{array}{c}\text { Complementarities in } \\
\text { production }\end{array}$ & $\begin{array}{c}\text { No complementarities } \\
\text { in production }\end{array}$ \\
\hline Predicted & $\alpha_{2}=0$ & $\alpha_{2}>0$ & $\alpha_{5}>0$ & $\alpha_{5}=0$ \\
parameter & & & $\omega_{2}>0$ & $\omega_{2}=0$ \\
estimates & & & $\omega_{5}>0$ & $\omega_{5}=0$ \\
\hline
\end{tabular}


Table 4: Variable Definitions

\begin{tabular}{|c|c|}
\hline Variable & Definition \\
\hline Offer Medicare & $\begin{array}{l}\text { Indicator variable }=1 \text { if HMO offers a Medicare } \\
\text { risk product, } 0 \text { otherwise }\end{array}$ \\
\hline Medicare member months & $\begin{array}{l}\text { Member month of health insurance coverage for a } \\
\text { Medicare enrollee (in 10000s) }\end{array}$ \\
\hline Private member months & $\begin{array}{l}\text { Member month of health insurance coverage for a } \\
\text { private, commercial enrollee (in 10000s) }\end{array}$ \\
\hline AAPCC & $\begin{array}{l}\text { Adjusted average per capita cost base rate (in } \\
\text { hundreds of dollars) }\end{array}$ \\
\hline Medigap & $\begin{array}{l}\text { Annual premium for AARP/Prudential Medigap } \\
\text { policy Package A (in hundreds of dollars) }\end{array}$ \\
\hline Gapmiss & $\begin{array}{l}\text { Indicator variable for missing Medigap premium } \\
\text { data }\end{array}$ \\
\hline Proportion $65-74$ & Proportion of population 65 to 74 years of age \\
\hline Proportion 75 and older & Proportion of population 75 to 84 years of age \\
\hline$\%$ of families in poverty & Percentage of families below the poverty level \\
\hline Young population change & $\begin{array}{l}\text { Estimated rate of change in population under } 65 \\
\text { years of age }\end{array}$ \\
\hline College & $\begin{array}{l}\text { Percentage of persons age } 25 \text { and older with four or } \\
\text { more years of college }\end{array}$ \\
\hline Pediatrician to active MD ratio & $\begin{array}{l}\text { Proportion of active physicians who are } \\
\text { pediatricians }\end{array}$ \\
\hline Subscriber policy-making & Subscribers maintain policy-making role \\
\hline HMO required option & $\begin{array}{l}\text { Employers must offer an HMO option in their } \\
\text { employees' health benefits package }\end{array}$ \\
\hline Rate approval & State approval for HMO premium rates \\
\hline Open enrollment & HMOs required to have an open enrollment period \\
\hline Missing regulation measures & Indicator variable for missing regulatory data \\
\hline Physician charges & $\begin{array}{l}\text { Average fee for office visit of intermediate } \\
\text { complexity (in hundreds of dollars) }\end{array}$ \\
\hline Nurse wage rate & Average nurse wage rate \\
\hline Supervisor wage rate & Average supervisor wage rate \\
\hline Per diem hospital rate & $\begin{array}{l}\text { Average hospital per diem rate (in hundreds of } \\
\text { dollars) }\end{array}$ \\
\hline Infant mortality & 5 year average (1988-92) infant mortality rate \\
\hline
\end{tabular}


Table 4: Variable Definitions (continued)

\begin{tabular}{|c|c|}
\hline Variable & Definition \\
\hline Federal qualification & $\begin{array}{l}\text { Indicator variable }=1 \text { if } \mathrm{HMO} \text { is federally qualified, } \\
0 \text { otherwise }\end{array}$ \\
\hline Age & Average age of HMOs in market \\
\hline Staff HMO & $\begin{array}{l}\text { Indicator variable }=1 \text { if HMO is a staff model, } 0 \\
\text { otherwise }\end{array}$ \\
\hline Network HMO & $\begin{array}{l}\text { Indicator variable }=1 \text { if } \mathrm{HMO} \text { is a network model, } 0 \\
\text { otherwise }\end{array}$ \\
\hline Group HMO & $\begin{array}{l}\text { Indicator variable }=1 \text { if } \mathrm{HMO} \text { is a group model, } 0 \\
\text { otherwise }\end{array}$ \\
\hline Mixed HMO & $\begin{array}{l}\text { Indicator variable }=1 \text { if } \mathrm{HMO} \text { is a mixed model, } 0 \\
\text { otherwise }\end{array}$ \\
\hline National affiliation - HMO & $\begin{array}{l}\text { Indicator variable }=1 \text { if HMO is affiliated with a } \\
\text { national HMO firm, } 0 \text { otherwise }\end{array}$ \\
\hline National affiliation - Other & $\begin{array}{l}\text { Indicator variable }=1 \text { if HMO is affiliated with a } \\
\text { national non-HMO firm (ie: insurer), } 0 \text { otherwise }\end{array}$ \\
\hline Blue Cross affiliation & $\begin{array}{l}\text { Indicator variable }=1 \text { if HMO is affiliated with Blue } \\
\text { Cross Blue Shield, } 0 \text { otherwise }\end{array}$ \\
\hline Profit status & $\begin{array}{l}\text { Indicator variable }=1 \text { if } \mathrm{HMO} \text { is has for-profit } \\
\text { status, } 0 \text { otherwise }\end{array}$ \\
\hline 1990 Indicator & Indicator variable $=1$ if year is 1990,0 otherwise \\
\hline 1991 Indicator & Indicator variable $=1$ if year is 1991,0 otherwise \\
\hline 1992 Indicator & Indicator variable $=1$ if year is 1992,0 otherwise \\
\hline 1993 Indicator & Indicator variable $=1$ if year is 1993,0 otherwise \\
\hline 1994 Indicator & Indicator variable $=1$ if year is 1994,0 otherwise \\
\hline 1995 Indicator & Indicator variable $=1$ if year is 1995,0 otherwise \\
\hline
\end{tabular}


Table 5: Descriptive Statistics

\begin{tabular}{|c|c|c|}
\hline Variable & Mean & Standard Deviation \\
\hline Offer Medicare & .197 & .398 \\
\hline $\begin{array}{l}\text { Medicare member months } \\
(10000 \mathrm{~s})\end{array}$ & 5.477 & 34.199 \\
\hline $\begin{array}{l}\text { Private member months } \\
(10000 \mathrm{~s})\end{array}$ & 98.215 & 294.45 \\
\hline AAPCC (100s) & 3.49 & .754 \\
\hline Medigap (100s) & 3.07 & 2.099 \\
\hline Gapmiss & .273 & .445 \\
\hline Proportion $65-74$ & .069 & .012 \\
\hline Proportion 75 and older & .05 & .011 \\
\hline$\%$ of families in poverty & 8.98 & 3.005 \\
\hline Young population change & -.015 & .023 \\
\hline College & 22.19 & 4.54 \\
\hline Pediatrician to active MD ratio & .068 & .011 \\
\hline Subscriber policy-making & .616 & .486 \\
\hline HMO required option & .23 & .421 \\
\hline Rate approval & .783 & .412 \\
\hline Open enrollment & .298 & .457 \\
\hline Missing regulations & .086 & .28 \\
\hline Physician charges (100s) & .474 & .103 \\
\hline Nurse wage rate & 16.28 & 1.66 \\
\hline Supervisor wage rate & 11.63 & 1.92 \\
\hline Per diem hospital rate (100s) & 7.31 & 1.58 \\
\hline Infant mortality & 9.218 & 1.46 \\
\hline Federal qualification & .541 & .498 \\
\hline Age & 9.91 & 7.53 \\
\hline Staff HMO & .062 & .241 \\
\hline Network HMO & .1 & .3 \\
\hline Group HMO & .087 & .282 \\
\hline Mixed HMO & .129 & .336 \\
\hline IPA HMO & .62 & .485 \\
\hline National affiliation - HMO & .16 & .366 \\
\hline National affiliation - Other & .304 & .46 \\
\hline Blue Cross affiliation & .151 & .358 \\
\hline Profit status & .683 & .465 \\
\hline 1990 Indicator & .192 & .394 \\
\hline 1991 Indicator & .164 & .371 \\
\hline 1992 Indicator & .165 & .372 \\
\hline 1993 Indicator & .16 & .366 \\
\hline 1994 Indicator & .152 & .359 \\
\hline 1995 Indicator & .166 & .372 \\
\hline $\mathrm{N}=2512$ & & \\
\hline
\end{tabular}


Table 6: Participation regression

\begin{tabular}{|c|c|c|c|}
\hline Dependent variable: Offer Medicare & $\begin{array}{l}\text { Parameter } \\
\text { estimate }\end{array}$ & $\begin{array}{l}\text { Standard } \\
\text { error }\end{array}$ & $\begin{array}{l}\text { Standard } \\
\text { error with } \\
\text { clustering }\end{array}$ \\
\hline Constant & -1.61 & 1.011 & 1.07 \\
\hline AAPCC & $.358 * * *$ & .101 & .112 \\
\hline Medigap & .0405 & .045 & .050 \\
\hline Gapmiss & -.336 & .272 & .272 \\
\hline Proportion 65-74 & $37.417 * * *$ & 10.87 & 11.74 \\
\hline Proportion 75 and older & $-32.42 * * *(* *)$ & 12.04 & 12.83 \\
\hline Percentage of families in poverty & -.0102 & .0223 & .025 \\
\hline Young population change & $-3.843^{*}$ (insig.) & 2.019 & 2.64 \\
\hline College & .0213 & .0167 & .018 \\
\hline Pediatrician to active MD ratio & -.062 & 5.32 & 5.21 \\
\hline Subscriber policy-making & .168 & .123 & .127 \\
\hline HMO required option & -.188 & .151 & .169 \\
\hline Open enrollment & -.02 & .132 & .147 \\
\hline Rate approval & -.057 & .175 & .215 \\
\hline Missing regulatory observations & -.1969 & .196 & .271 \\
\hline Physician charges & .294 & .947 & .957 \\
\hline Nurse wage rate & $-.091 * *$ & .0369 & .041 \\
\hline Supervisor wage rate & -.0137 & .0181 & .019 \\
\hline Per diem hospital rate & -.015 & .0327 & .034 \\
\hline Infant mortality & $-.1207 * * *$ & .044 & .045 \\
\hline Federal qualification & $.4734 * * *$ & .0969 & .105 \\
\hline Age & $.0395 * * *$ & .0073 & .008 \\
\hline Staff HMO & $.306^{*}$ (insig) & .173 & .192 \\
\hline Network HMO & $.247 *$ & .135 & .144 \\
\hline Group HMO & $.326^{* *}$ & .162 & .149 \\
\hline Mixed HMO & $.3949 * * *$ & .106 & .121 \\
\hline National affiliation - HMO & $.431 * * *$ & .129 & .130 \\
\hline National affiliation - Other & .1 & .116 & .135 \\
\hline Blue Cross Blue Shield affiliation & -.047 & .149 & .148 \\
\hline Profit status & .051 & .124 & .139 \\
\hline 1991 indicator & $-.409 *$ & .241 & .214 \\
\hline 1992 indicator & -.258 & .272 & .259 \\
\hline 1993 indicator & $-.428 *$ (insig) & .281 & .274 \\
\hline 1994 indicator & -.314 & .292 & .290 \\
\hline 1995 indicator & -.341 & .3101 & .316 \\
\hline $\mathrm{N}=2437$ & & & \\
\hline
\end{tabular}

* Significant at the 10\% level ** Significant at the 5\% level $* * *$ Significant at the $1 \%$ level Notation in parentheses indicates significance using the standard error with clustering 
Table 7: Quantity regressions

\begin{tabular}{|c|c|c|c|c|c|c|}
\hline & \multicolumn{2}{|c|}{$\begin{array}{l}\text { Dependent variable: } \\
\text { Medicare quantity } \\
\text { (no selection correction) }\end{array}$} & \multicolumn{2}{|c|}{$\begin{array}{l}\text { Dependent variable: } \\
\text { Medicare quantity }\end{array}$} & \multicolumn{2}{|c|}{$\begin{array}{l}\text { Dependent variable: } \\
\text { Private quantity }\end{array}$} \\
\hline & $\begin{array}{l}\text { Parameter } \\
\text { Estimate }\end{array}$ & $\begin{array}{l}\text { Robust } \\
\text { Standard } \\
\text { Error }\end{array}$ & $\begin{array}{l}\text { Parameter } \\
\text { Estimate }\end{array}$ & $\begin{array}{l}\text { Robust } \\
\text { Standard error }\end{array}$ & $\begin{array}{l}\text { Parameter } \\
\text { Estimate }\end{array}$ & $\begin{array}{l}\text { Robust } \\
\text { Standard } \\
\text { error }\end{array}$ \\
\hline Offer Medicare & $\ldots$. & $\ldots \ldots$ & $\ldots .$. & $\ldots .$. & -93.112 & 319.502 \\
\hline Medicare member months & $\ldots \ldots$ & $\ldots \ldots$ & $\ldots .$. & $\ldots .$. & $6.524 *$ & 3.968 \\
\hline Private member months & $.117 * * *$ & .033 & $.1239 * * *$ & .0398 & & \\
\hline AAPCC & -2.39 & 6.64 & .714 & 8.69 & 3.463 & 19.792 \\
\hline Medigap & $6.67 * *$ & 2.81 & $7.278^{* *}$ & 3.395 & $\ldots \ldots$ & $\ldots$. \\
\hline Gapmiss & 24.19 & 17.17 & 21.02 & 17.497 & $\ldots \ldots$ & $\ldots .$. \\
\hline Proportion $65-74$ & 897.18 & 771.62 & 1317.67 & 994.8 & $\ldots .$. & $\ldots \ldots$ \\
\hline Proportion 75 and older & -478.22 & 625.47 & -885.65 & 1014.66 & $\ldots \ldots$ & $\ldots \ldots$ \\
\hline$\%$ Families in poverty & $\ldots \ldots$ & $\ldots \ldots$ & $\ldots .$. & $\ldots .$. & -.466 & 4.065 \\
\hline Young population change & $\ldots \ldots$ & $\ldots \ldots$ & $\ldots .$. & $\ldots \ldots$ & $650.03 * *$ & 327.427 \\
\hline College & $\ldots \ldots$ & $\ldots \ldots$ & $\ldots .$. & $\ldots \ldots$ & 2.497 & 2.477 \\
\hline $\begin{array}{l}\text { Pediatrician to active MD } \\
\text { ratio }\end{array}$ & $\ldots \ldots$ & $\ldots$. & $\ldots .$. & $\ldots \ldots$ & 847.24 & 611.14 \\
\hline Subscriber policy-making & $\ldots \ldots$ & $\ldots \ldots$ & $\ldots .$. & $\ldots \ldots$ & 25.208 & 30.116 \\
\hline Required HMO option & $\ldots \ldots$ & $\ldots \ldots$ & $\ldots \ldots$ & $\ldots \ldots$ & 2.168 & 13.207 \\
\hline Rate approval & $\ldots \ldots$ & $\ldots \ldots$ & $\ldots \ldots$. & $\ldots \ldots$ & -43.563 & 35.225 \\
\hline Open enrollment & $\ldots \ldots$ & $\ldots \ldots$ & $\ldots \ldots$ & $\ldots . .$. & 1.164 & 19.804 \\
\hline Missing regulations & & & $\ldots \ldots$ & $\ldots \ldots$ & -51.751 & 36.099 \\
\hline Physician charges & 69.77 & 71.97 & 80.55 & 83.62 & -70.678 & 104.389 \\
\hline Nurse wage rate & $-5.59 *$ & 3.19 & -7.18 & 4.79 & 5.013 & 4.751 \\
\hline Supervisor wage rate & .044 & 1.15 & .2945 & 1.37 & 1.363 & 3.333 \\
\hline Per diem hospital rate & -.138 & 2.30 & .219 & 2.24 & -2.657 & 5.111 \\
\hline Infant mortality & -2.60 & 2.43 & -4.203 & 3.478 & -4.969 & 7.875 \\
\hline Age & -.034 & .704 & .18 & .786 & $5.443 *$ & 3.301 \\
\hline Staff HMO & .648 & 10.81 & 5.773 & 16.943 & -51.139 & 37.242 \\
\hline Network HMO & 18.63 & 13.75 & 22.855 & 16.616 & $-37.349 * *$ & 16.809 \\
\hline Group HMO & $-24.99^{*}$ & 14.06 & $-21.616^{*}$ & 13.747 & $58.338^{*}$ & 33.677 \\
\hline Mixed HMO & 13.20 & 13.60 & 18.01 & 18.78 & 9.838 & 49.793 \\
\hline National affiliation - HMO & 18.37 & 12.37 & 21.046 & 14.24 & 17.587 & 37.005 \\
\hline National affiliation - Other & 2.01 & 8.32 & 1.845 & 8.65 & 13.372 & 19.001 \\
\hline $\begin{array}{l}\text { Blue Cross Blue Shield } \\
\text { affiliation }\end{array}$ & -14.94 & 14.12 & -16.21 & 14.22 & 27.454 & 25.531 \\
\hline Profit status & 1.823 & 5.154 & 2.526 & 5.99 & -13.202 & 14.151 \\
\hline 1991 indicator & -4.43 & 13.55 & -9.003 & 17.73 & 2.467 & 5.725 \\
\hline 1992 indicator & -2.09 & 17.59 & -4.943 & 19.95 & 1.775 & 14.949 \\
\hline 1993 indicator & -7.024 & 16.67 & -11.33 & 20.786 & 20.456 & 14.382 \\
\hline 1994 indicator & -6.07 & 16.90 & -8.947 & 19.461 & 19.912 & 18.022 \\
\hline 1995 indicator & -12.81 & 17.84 & -15.606 & 20.44 & 43.313 & $25.05^{*}$ \\
\hline Lambda & $\ldots$. & $\ldots \ldots$ & 14.41 & 28.48 & $\ldots \ldots$ & $\ldots \ldots$ \\
\hline Constant & 20.47 & 52.96 & 6.56 & 59.24 & -75.525 & 79.208 \\
\hline Number of observations & 490 & & 490 & & 2437 & \\
\hline F-statistic & \multicolumn{2}{|c|}{$\begin{array}{l}F(25,168)=2.92 \\
\text { Prob }>F=.0000\end{array}$} & \multicolumn{2}{|c|}{$\begin{array}{l}F(26,168)=2.28 \\
\text { Prob }>F=.0009\end{array}$} & \multicolumn{2}{|c|}{$\begin{array}{l}\mathrm{F}(31,562)=3.39 \\
\text { Prob }>\mathrm{F}=.00000\end{array}$} \\
\hline
\end{tabular}

* Significant at the $10 \%$ level ** Significant at the 5\% level *** Significant at the $1 \%$ level 
Table 8: Predicted Probabilities for HMO subsample ( $\mathrm{N}=84)$

\begin{tabular}{|l|l|l|}
\hline AAPCC Payment Rate & Designation & Predicted Probability \\
\hline$\$ 251$ & Minimum & .0785 \\
\hline$\$ 300$ & Median & .1075 \\
\hline$\$ 341^{*}$ & Maximum & .1373 \\
\hline
\end{tabular}

*1998 Medicare+Choice minimum payment level deflated to 1995 dollars.

Table 9: Sunk Costs of Entry Estimates

\begin{tabular}{|l|l|l|l|l|l|}
\hline $\begin{array}{l}\text { Geographic } \\
\text { Region }\end{array}$ & $\begin{array}{l}\text { Medicare } \\
\text { member } \\
\text { months }\end{array}$ & $\begin{array}{l}\text { Medicare } \\
\text { price }\end{array}$ & $\begin{array}{l}\text { Profit per dollar } \\
\text { of revenue }\end{array}$ & $\begin{array}{l}\text { Estimated sunk } \\
\text { costs of entry }\end{array}$ & $\begin{array}{l}\text { Sunk cost per } \\
\text { member month }\end{array}$ \\
\hline & & & & & \\
\hline West & 46578 & $\$ 381$ & .05 & $\$ 887,387$ & $\$ 19.05$ \\
\hline & & & .10 & $1,774,621$ & 38.10 \\
\hline & & .20 & $3,549,243$ & 76.20 \\
\hline & & & & & \\
\hline Central & & .05 & $\$ 2,356,105$ & $\$ 20.45$ \\
\hline & 115213 & $\$ 409$ & .10 & $4,712,211$ & 40.90 \\
\hline & & & .20 & $9,424,423$ & 81.80 \\
\hline & & & & & \\
\hline East & & $\$ 481$ & .05 & $\$ 2,015,991$ & $\$ 24.05$ \\
\hline & 83825 & & .10 & $4,031,982$ & 48.10 \\
\hline & & & .20 & $8,063,965$ & 96.20 \\
\hline
\end{tabular}




\section{References}

Adamache, Killard and L. Rossiter, 1986, The Entry of HMOs into the Medicare Market: Implications for TEFRA's Mandate, Inquiry 23, 349-364.

Dallek, Geraldine, 1996, The Crushing Costs of Medicare Supplemental Policies. (Families USA Foundation, Washington DC).

Danzon, P.M., 1982, Hospital 'profits': The effect of reimbursement policies, Journal of Health Economics 1, 29-52.

Given, Ruth S., 1996, Economies of Scale and Scope as an Explanation of Merger and Output Diversification Activities in the Health Maintenance Organization Industry, Journal of Health Economics 15, 685-713.

Gourieroux, C., A. Monfort, and A. Trognon, 1984, Pseudo Maximum Likelihood Methods: Theory, Econometrica 52, 681-700.

Greene, William H., 1993, Econometric Analysis - 2nd Edition, (Prentice Hall, Englewood Cliffs, New Jersey).

Greene, William H., 1997, Econometric Analysis - 3rd Edition, (Prentice Hall, Englewood Cliffs, New Jersey).

Hansmann, H., 1987, Economic theories of non-profit organization, in: W. Powell, ed., The nonprofit sector: A research handbook, (Yale University Press, New Haven, CT).

HCIA, 1990-1995, HMO data base, Diskette series, User's manual (Baltimore, MD).

Health Care Financing Administration, 1998, http://www.hcfa.gov

Hellinger, Fred J., 1995, Selection Bias in HMOs and PPOs: A Review of the Evidence, Inquiry $32,135-142$.

InterStudy, 1990-1995, InterStudy edge (Interstudy, Excelsior, MN).

Langwell, Kathryn and James Hadley, 1986, Capitation and the Medicare program: history, issues, and evidence, Health Care Financing Review 1986 Annual Supplement, 9-20.

Langwell, Kathryn and James Hadley., 1982, Evaluation of the Medicare Competition Demonstrations, Health Care Financing Review 2, 65-79.

Liang, Kung-Yee and Scott Zeger, 1986, Longitudinal data analysis using generalized linear models, Biometrika 73, 13-22. 
McCullagh, P. and J.A. Nelder, 1983, Generalized Linear Models - Second Edition, (Chapman \& Hall, New York).

National Association of Insurance Commisioners and the Health Care Financing Administration of the U.S. Department of Health and Human Services, 1996, Guide to Health Insurance for People with Medicare.

Pauly, M.V., 1987, Nonprofit firms in medical markets, American Economic Review 77, 257-262.

Porell, Frank and Winston Turner, 1990, Biased Selection Under the Senior Health Plan Prior Use Capitation Formula, Inquiry 27, 39-49.

Porell, Frank and Stanley Wallack, 1990, Medicare risk contracting: Determinants of market entry, Health Care Financing Review 12, 75-84.

Serrato, C., R. Brown, and J.Bergeron, 1995, Why do so few HMOs offer Medicare risk plans in rural areas?, Health Care Financing Review 17, 85-97.

Smolka, Gerry. American Association of Retired Persons, Washington DC. Personal correspondence, 1996.

Staiger, Douglas and James Stock, 1997, Instrumental Variables Regression with Weak Instruments, Econometrica 65, 557-86.

StataCorp, 1997, Stata Statistical Software: Release 5.0 College Station, TX: Stata Corporation.

United States Bureau of the Census, Statistical Abstract of the United States $\left(117^{\text {th }}\right.$ edition), Washington DC, 1997.

United States Department of Commerce, 1996, Area Resource File, Prepared for the Bureau of Health Professions by Applied Management Sciences, Available through the National Technical Information Service.

United States Department of Health and Human Services, 1996. Medicare and Medicaid Statistical Supplement, Health Care Financing Review, 124-133.

United States General Accounting Office, 1997, Medicare HMO Enrollment - Area Differences Affected by Factors Other Than Payment Rates, Report to the Honorable John F. Kerry, U.S. Senate.

Wholey, Douglas, Roger Feldman, and Jon Christianson, 1995, The effect of market structure on HMO premiums, Journal of Health Economics 14, 81-105.

Wholey, Douglas, Roger Feldman, Jon Christianson, and John Engberg, 1996, Scale and 
Scope Economies Among Health Maintenance Organizations, Journal of Health Economics 15, 657-684.

Wilensky, Gail, December 28,1995, The Score on Medicare Reform - Minus the Hype and Hyperbole, The New England Journal of Medicine 333, 1774-1777.

Zarabozo, Carlos and Jean LeMasurier, 1995, Medicare and Managed Care in: P. Kongstvedt, ed., Essentials of Managed Health Care, (Aspen Publishers, Gaithersburg, MD).

Zarabozo, Carlos and Jean LeMasurier, 1996, Medicare Risk Plans: The Health Plan's View in: P. Kongstvedt, ed., The Managed Health Care Handbook, (Aspen

Publishers: Gaithersburg, MD). 


\section{Appendix}

\section{Maximization Problem and Comparative Statics}

Profit-maximization problem

$\operatorname{Max} \pi=P_{p} Q_{p}+P_{m} Q_{m}-C_{1} Q_{m}-C_{2} Q_{p}-C_{3} Q_{m} Q_{p}-C_{4} Q_{m}{ }^{2}-C_{5} Q_{p}{ }^{2}-C_{6} z Q_{m}-C_{7} z-C_{8} z^{2}$

Qp, z

subject to:

(1) $Q_{m} \geq 0$

(2) $Q_{p}-Q_{m} \geq 0$

(3) $Q_{m R}-Q_{m} \geq 0$

To solve this constrained optimization problem, we set up a Lagrangian expression:

$$
\begin{aligned}
& L=P_{p} Q_{p}+P_{m} Q_{m}-C_{1} Q_{m}-C_{2} Q_{p}-C_{3} Q_{p} Q_{m}-C_{4} Q_{m}{ }^{2}-C_{5} Q_{p}{ }^{2}-C_{6} z Q_{m}-C_{7} z-C_{8} z^{2}+\lambda Q_{m} \\
& +\rho\left(Q_{p}-Q_{m}\right)+\sigma\left(Q_{m R}-Q_{m}\right)=0
\end{aligned}
$$

Taking the first order conditions:

(1)

$$
\begin{aligned}
\frac{\partial L}{\partial Q_{p}}= & P_{p}+Q_{p}\left[\frac{\partial P_{p}}{\partial Q_{p}}+\frac{\partial P_{p}}{\partial Q_{m}} \cdot \frac{\partial Q_{m}}{\partial Q_{p}}\right]+P_{m} \frac{\partial Q_{m}}{\partial Q_{p}}-C_{1} \frac{\partial Q_{m}}{\partial Q_{p}}-C_{2}-C_{3}\left[Q_{m}+Q_{p} \frac{\partial Q_{m}}{\partial Q_{p}}\right]-2 C_{4} \frac{\partial Q_{m}}{\partial Q_{p}}-2 C_{5} Q_{p} \\
& -C_{6} z \frac{\partial Q_{m}}{\partial Q_{p}}+\lambda \frac{\partial Q_{m}}{\partial Q_{p}}+\rho\left(1-\frac{\partial Q_{m}}{\partial Q_{p}}\right)+\sigma\left(\frac{\partial Q_{m R}}{\partial Q_{p}}-\frac{\partial Q_{m}}{\partial Q_{p}}\right)=0
\end{aligned}
$$

(2)

$$
\begin{aligned}
\frac{\partial L}{\partial z}= & Q_{p}\left[\frac{\partial P_{p}}{\partial Q_{m}} \cdot \frac{\partial Q_{m}}{\partial z}\right]+P_{m} \frac{\partial Q_{m}}{\partial z}-C_{1} \frac{\partial Q_{m}}{\partial z}-C_{3} Q_{p} \frac{\partial Q_{m}}{\partial z}-2 C_{4} Q_{m} \frac{\partial Q_{m}}{\partial z}-C_{6}\left[z \frac{\partial Q_{m}}{\partial z}+Q_{m}\right] \\
& -C_{7}-2 C_{8} z+\lambda \frac{\partial Q_{m}}{\partial z}-\rho \frac{\partial Q_{m}}{\partial z}-\sigma \frac{\partial Q_{m}}{\partial z}=0
\end{aligned}
$$

(3) $\frac{\partial L}{\partial \lambda}=Q_{m} \geq 0$

(4) $\frac{\partial L}{\partial \rho}=Q_{p}-Q_{m} \geq 0$ 
(5) $\frac{\partial L}{\partial \sigma}=Q_{m R}-Q_{m} \geq 0$

(6) $\lambda Q_{m}=0$

(7) $\rho\left(Q_{p}-Q_{m}\right)=0$

(8) $\sigma\left(Q_{R}-Q_{m}\right)=0$

$\frac{\partial^{2} L}{\partial Q_{p}{ }^{2}}=2 \frac{\partial P_{p}}{\partial Q_{p}}+\frac{\partial P_{p}}{\partial Q_{m}} \cdot \frac{\partial Q_{m}}{\partial Q_{p}}-2 C_{5}<0$

The second order conditions can be expressed as the following:

$$
\begin{aligned}
& \frac{\partial^{2} L}{\partial z^{2}}=-2 C_{4}\left(\frac{\partial Q_{m}}{\partial z}\right)^{2}-2 C_{6} \frac{\partial Q_{m}}{\partial z}-2 C_{8}<0 \\
& \frac{\partial^{2} L}{\partial Q_{p} \partial z}=\frac{\partial^{2} L}{\partial z \partial Q_{p}}=\frac{\partial P_{p}}{\partial Q_{m}} \cdot \frac{\partial Q_{m}}{\partial z}-C_{3} \frac{\partial Q_{m}}{\partial z}-C_{6} \frac{\partial Q_{m}}{\partial Q_{p}}>0
\end{aligned}
$$

To ensure a maximum, the following criteria must hold:

$$
\left(\frac{\partial^{2} L}{\partial Q_{p}{ }^{2}}\right)\left(\frac{\partial^{2} L}{\partial z^{2}}\right)-\left(\frac{\partial^{2} L}{\partial Q_{p} \partial z}\right)^{2}>0 \text { and }\left(\frac{\partial^{2} L}{\partial Q_{p}{ }^{2}}\right)<0 .
$$

\section{Predicted Effects:}

Firms are demand-constrained (Case III):

When firms are demand-constrained, an individual firm's Medicare quantity is determined by the constraint. Firms choose the level of quality ( $\mathrm{z}$ ), that corresponds to $\mathrm{Q}_{\mathrm{m}}\left(\mathrm{z}, \mathrm{X}_{\mathrm{m}}, \mathrm{Q}_{\mathrm{p}}\right)=\mathrm{Q}_{\mathrm{mR}}\left(\mathrm{X}_{\mathrm{m}}, \mathrm{Q}_{\mathrm{p}}\right)$, such that $\mathrm{z}$ is a function of residual market demand, Medicare demand shifters, and private quantity. We proceed by substituting residual market demand for individual firm demand in the profit-maximization problem, taking the first order condition with respect to private quantity, and then determining the predicted effects of the Medicare price and demand shifters on a firm's private and Medicare quantities. Note, here we make the assumption that there are no diseconomies of scope in production.

$$
\underset{Q_{p}}{\operatorname{Max}} \pi=P_{p} Q_{p}+P_{m} Q_{m R}-C_{1} Q_{m R}-C_{2} Q_{p}-C_{3} Q_{m R} Q_{p}-C_{4} Q_{m R}^{2}-C_{5} Q_{p}^{2}-C_{6} z Q_{m R}-C_{7} z-C_{8} z^{2}
$$


First-Order Condition:

$$
\begin{aligned}
\frac{\partial \pi}{\partial Q_{p}}= & P_{p}+Q_{p}\left[\frac{\partial P_{p}}{\partial Q_{p}}+\frac{\partial P_{p}}{\partial Q_{m R}} \cdot \frac{\partial Q_{m R}}{\partial Q_{p}}\right]+P_{m} \frac{\partial Q_{m R}}{\partial Q_{p}}-C_{1} \frac{\partial Q_{m R}}{\partial Q_{p}}-C_{2}-C_{3}\left[Q_{m R}+Q_{p} \frac{\partial Q_{m R}}{\partial Q_{p}}\right] \\
& -2 C_{4} Q_{m R} \frac{\partial Q_{m R}}{\partial Q_{p}}-2 C_{5} Q_{p}-C_{6}\left[z \frac{\partial Q_{m R}}{\partial Q_{p}}+Q_{m R} \frac{\partial z}{\partial Q_{m R}} \cdot \frac{\partial Q_{m R}}{\partial Q_{p}}\right]-C_{7} \frac{\partial z}{\partial Q_{m R}} \cdot \frac{\partial Q_{m R}}{\partial Q_{p}}-2 C_{8} z \frac{\partial z}{\partial Q_{m R}} \cdot \frac{\partial Q_{m R}}{\partial Q_{p}}=0
\end{aligned}
$$

Case III (assuming no complementarities):

$$
\begin{array}{ll}
\frac{\partial Q_{p}}{\partial P_{m}}=0 & \frac{\partial Q_{m}}{\partial P_{m}}=0 \\
\frac{\partial Q_{p}}{\partial X_{p}}>0 & \frac{\partial Q_{m}}{\partial X_{p}}=0 \\
\frac{\partial Q_{p}}{\partial X_{m}}=0 & \frac{\partial Q_{m}}{\partial X_{m}}<0
\end{array}
$$

Firms are unconstrained (Case IV):

Using first-order conditions (1) and (2) from Appendix 1, we form the total differentials and derive the predicted effects below.

Recall:

$$
\begin{aligned}
& P_{P}=\frac{-1}{\theta_{1}} Q_{p}+\frac{\theta_{0}}{\theta_{1}}+\frac{\theta_{2}}{\theta_{1}} X_{p}+\frac{\theta_{3}}{\theta_{1}} Q_{m} \\
& Q_{m}=m_{1} z+m_{2} X_{m}+m_{3} Q_{p}
\end{aligned}
$$


(1)

$$
\begin{aligned}
d\left[\frac{\partial \pi}{\partial Q_{p}}\right]= & \left(\frac{-2}{\theta_{1}}+\frac{\theta_{2}}{\theta_{1}} m_{3}-C_{3} m_{3}-2 C_{5}\right) d Q_{p}+\left(\frac{\theta_{3}}{\theta_{1}} m_{1}-C_{3} m_{1}-C_{6} m_{3}\right) d z+m_{3} d P_{m}+ \\
& \left(\frac{\theta_{3}}{\theta_{1}} m_{2}-C_{3} m_{2}\right) d X_{m}+\left(\frac{\theta_{2}}{\theta_{1}}\right) d X_{p}+\left(1-m_{3}\right) d \rho-m_{3} d C_{1}-1 d C_{2}-\left(Q_{m}+Q_{p} m_{3}\right) d C_{3} \\
& -2 m_{3} d C_{4}-2 Q_{p} d C_{5}-z m_{3} d C_{6}+0 d C_{7}+0 d C_{8}+\left(\frac{\partial Q_{m R}}{\partial Q_{p}}-m_{3}\right) d \sigma+m_{3} d \lambda=0
\end{aligned}
$$

$$
\begin{aligned}
d\left[\frac{\partial \pi}{\partial z}\right]= & \left(\frac{\theta_{3}}{\theta_{1}} m_{1}-C_{3} m_{1}-C_{6} m_{3}\right) d Q_{p}-\left(2\left(C_{4} m_{1}^{2}+C_{6} m_{1}+C_{8}\right)\right) d z+m_{1} d P_{m}+0 d X_{p} \\
& \left(-2 C_{4} m_{1} m_{2}-C_{6} m_{2}\right) d X_{m}-m_{1} d C_{1}-0 d C_{2}-m_{1} Q_{p} d C_{3}-2 m_{1} Q_{m} d C_{4}+0 d C_{5} \\
& -\left(m_{1} z-Q_{m}\right) d C_{6}-1 d C_{7}-2 z d C_{8}-m_{1} d \rho-m_{1} d \sigma=0
\end{aligned}
$$

Case IV (assuming no demand or cost complementarities):

$$
\begin{array}{ll}
\frac{d Q_{p}}{d P_{m}}=0 & \frac{d Q_{m}}{d P_{m}}>0 \\
\frac{d Q_{p}}{d X_{m}}=0 & \frac{d Q_{m}}{d X_{m}}=? \\
\frac{d Q_{p}}{d X_{p}}>0 & \frac{d Q_{m}}{d X_{p}}=0
\end{array}
$$




\section{Econometric Estimation}

When one cannot assume that the error terms of observations are independent and identically distributed, then specifying the appropriate probability density function to do maximum likelihood estimation may be very complex. One alternative approach is to specify a quasi-likelihood function, which requires the following two things to occur. First, one needs to be able to specify the relationship between the mean and the variance of the dependent variable. And second, the unknown distribution of the dependent variable must be of the linear exponential family, which includes such distributions as binomial, normal, and Poisson (Gourieroux, Monfort, and Trognon, 1984; McCullagh and Nelder, 1983). Once the quasi-likelihood is specified, then the parameter estimates can be found by solving the corresponding quasi-score functions simultaneously.

For estimation of the participation regression, we use generalized estimating equations (GEE), which is the multivariate analogue of quasi-likelihood estimation. We specify the distribution of the dependent variable as binomial. Furthermore, to address the issue of unobserved firm-specific effects, we specify an exchangeable correlation structure (corresponding to the presence of random effects), and this "working correlation matrix" is also incorporated into the maximization problem. Using this method, we are able to obtain consistent parameter estimates. See Liang and Zeger (1986) and Zeger and Liang (1992) for additional discussion of GEE. For the enrollment equations, parameter estimates are calculated using traditional instrumental variables estimation.

The standard errors for both the participation and enrollment regressions are computed using the method described below, which permits within HMO-cluster correlation and allows for the possibility that residuals across HMO clusters are not identically distributed. Here, a cluster includes all observations over the time period of our sample that correspond to a single HMO.

The Huber/White/sandwich estimator of variance is defined as the following:

$v=q_{c} \hat{V}\left(\sum_{k=1}^{M} u_{k}^{(G) '} u_{k}^{(G)}\right) \hat{V}$

$u_{k}^{(G)}=\sum_{j \in G_{k}} u_{j}$

where:

$G_{k}$ denotes each cluster, $k=1, \ldots M$

$\hat{V}=\left(X^{\prime} X\right)^{-1}$

$u_{j}=\left(y_{j}-x_{j} b\right) \hat{x}_{j}$ and is a row vector of scores, where $j$ denotes individual observations in cluster $G_{k}$

$q_{c}=\frac{N-1}{N-k} \cdot \frac{M}{M-1}, N=$ number of observations, $M=$ number of clusters, $k=$ number of regressors 
Computation of the term in parentheses can be summarized in the following manner. First, the score $\left(\mathrm{u}_{\mathrm{j}}\right)$ is calculated for each observation within a cluster. Scores are then summed up over the $\mathrm{j}$ observations in a cluster, producing a row vector. The outer product is then calculated, which results in a matrix of dimension equal to the number of regressors. One matrix is constructed for each cluster and then these matrices are summed over the clusters in the sample, giving rise to the matrix in parentheses.

By using this method, we have addressed the problem of obtaining consistent standard error estimates given the presence of within-cluster correlation, since we rely only on "between" cluster variation in the computation of this estimator of variance. Additional discussion may be found in the Stata Reference Manual, 1997. 
To order any of these papers in hard copy, see instructions at the end of this list. To subscribe to all NBER Working Papers or the papers in a single area, see instructions inside the back cover.

Number

7333

7334

7335

7336

7337

7338

7340

7341

7342

7343

7344

7345

7346
Author(s)

James L. Heckman

Rajesh K. Aggarwal

Andrew A. Samwick

Rajesh K. Aggarwal

Andrew A. Samwick

Richard Portes Hélène Rey

Kathryn M. Dominguez

Jeffrey A. Frankel

Axel Börsch-Supan

Hylke Vandenbussche

Jozef Konings

Linda Springael

Robert F. Engle

Simone Manganelli

David C. King

Richard J. Zeckhauser

Christina Paxson

Jane Waldfogel

Michael Hout

Harvey S. Rosen

Jean O. Lanjouw

Mark Schankerman

Geert Bekaert

Steven R. Grenadier

Thomas N. Hubbard $\underline{\text { Title }}$

Date

Causal Parameters and Policy Analysis in Economics: $\quad 9 / 99$

A Twentieth Century Retrospective

Performance Incentives Within Firms: The Effect of $9 / 99$ Managerial Responsibility

Empire-Builders and Shirkers: Investment, Firm $9 / 99$

Performance, and Managerial Incentives

The Determinants of Cross-Border Equity Flows

$9 / 99$

The Market Microstructure of Central Bank Intervention $9 / 99$

No Single Currency Regime is Right for all Countries $\quad 9 / 99$ or at All Times

Incentive Effects of Social Security Under an Uncertain 9/99 Disability Option

Import Diversion under European Antidumping Policy

$9 / 99$

CAViaR: Conditional Value at Risk By Quantile $9 / 99$ Regression

Congressional Vote Options

$9 / 99$

Work, Welfare, and Child Maltreatment

$9 / 99$

Self-Employment, Family Background, and Race

$9 / 99$

The Quality of Ideas: Measuring Innovation with $9 / 99$ Multiple Indicators

Stock and Bond Pricing in an Affine Economy

How Wide Is the Scope of Hold-Up-Based Theories?

You can download these and other papers at the NBER Web site:

www.nber.org

Free searchable abstracts are also available at the site. 
To order any of these papers in hard copy, see instructions at the end of this list. To subscribe to all NBER Working Papers or the papers in a single area, see instructions inside the back cover.

\begin{tabular}{|c|c|}
\hline Number & Author(s) \\
\hline 7348 & Jonathan Gruber \\
\hline 7349 & Edward P. Lazear \\
\hline 7350 & Tamim Bayoumi \\
\hline 7351 & $\begin{array}{l}\text { Taizo Motonishi } \\
\text { Hiroshi Yoshikawa }\end{array}$ \\
\hline 7352 & $\begin{array}{l}\text { Daron Acemoglu } \\
\text { Robert Shimer }\end{array}$ \\
\hline 7353 & $\begin{array}{l}\text { Jeff Grogger } \\
\text { Charles Michalopoulos }\end{array}$ \\
\hline 7354 & Roberto Rigobon \\
\hline 7355 & $\begin{array}{l}\text { Ricardo J. Caballero } \\
\text { Mohamad L. Hammour }\end{array}$ \\
\hline 7356 & $\begin{array}{l}\text { Alec Ian Gershberg } \\
\text { Michael Grossman } \\
\text { Fred Goldman }\end{array}$ \\
\hline 7357 & Robert E. Lipsey \\
\hline 7358 & Vernon Henderson \\
\hline 7359 & $\begin{array}{l}\text { Iain Cockburn } \\
\text { Rebecca Henderson } \\
\text { Scott Stern }\end{array}$ \\
\hline 7360 & $\begin{array}{l}\text { Douglas Holtz-Eakin } \\
\text { Jolnn W. Phillips } \\
\text { Harvey S. Rosen }\end{array}$ \\
\hline 7361 & $\begin{array}{l}\text { Bong-Chan Kho } \\
\text { René M. Stulz }\end{array}$ \\
\hline
\end{tabular}

Title

$\underline{\text { Date }}$

The Wealth of the Unemployed: Adequacy and

Implications for Unemployment Insurance

Educational Production

9/99

The Morning After: Explaining the Slowdown in

Japanese Growth in the 1990s

Causes of the Long Stagnation of Japan during the

9/99

1990's: Financial or Real?

Productivity Gains From Unemployment Insurance

$9 / 99$

Welfare Dynamics under Time Limits

$9 / 99$

On the Measurement of the International Propagation

$9 / 99$

of Shocks

The Cost of Recessions Revisited: A Reverse-

$9 / 99$

Liquidationist View

Competition and the Cost of Capital Revisited: Special $\quad 9 / 99$ Authorities and Underwriters in the Market for Taxexempt Hospital Bonds

Foreign Production by U.S. Firms and Parent Firm

$9 / 99$

Employment

Marshall's Economies

$9 / 99$

The Diffusion of Science-Driven Drug Discovery:

$9 / 99$

Organizational Change in Pharmaceutical Research

Estate Taxes, Life Insurance, and Small Business

$9 / 99$

Banks, the IMF, and the Asian Crisis

$9 / 99$

You can download these and other papers at the NBER Web site:

www.nber.org

Free searchable abstracts are also available at the site. 
To order any of these papers in hard copy, see instructions at the end of this list. To subscribe to all NBER Working Papers or the papers in a single area, see instructions inside the back cover.

\begin{tabular}{|c|c|}
\hline Number & Author(s) \\
\hline 7362 & $\begin{array}{l}\text { Jagadeesh Gokhale } \\
\text { Laurence J. Kotlikoff }\end{array}$ \\
\hline 7363 & $\begin{array}{l}\text { Bruce D. Meyer } \\
\text { Dan T. Rosenbaum }\end{array}$ \\
\hline 7364 & $\begin{array}{l}\text { Dani Rodrik } \\
\text { Andrés Velasco }\end{array}$ \\
\hline 7365 & $\begin{array}{l}\text { Michael D. Bordo } \\
\text { Lars Jonung }\end{array}$ \\
\hline 7366 & Emmanuel Sacz \\
\hline 7367 & Emmanuel Saez \\
\hline 7368 & $\begin{array}{l}\text { Alan L. Gustman } \\
\text { Thomas L. Steinmeier }\end{array}$ \\
\hline 7369 & $\begin{array}{l}\text { Wolfgang Keller } \\
\text { Arik Levinson }\end{array}$ \\
\hline 7370 & $\begin{array}{l}\text { Michael Baker } \\
\text { Gary Solon }\end{array}$ \\
\hline 7371 & $\begin{array}{l}\text { Michael Baker } \\
\text { Nicole M. Fortin }\end{array}$ \\
\hline 7372 & $\begin{array}{l}\text { B. Douglas Bernheim } \\
\text { Lorenzo Forni } \\
\text { Jagadeesh Gokhale } \\
\text { Laurence J. Kotlikoff }\end{array}$ \\
\hline 7373 & $\begin{array}{l}\text { Paul A. David } \\
\text { Bronwyn H. Hall } \\
\text { Andrew A. Toole }\end{array}$ \\
\hline 7374 & $\begin{array}{l}\text { Peter Cappelli } \\
\text { David Neumark }\end{array}$ \\
\hline
\end{tabular}

$\underline{\text { Title }}$

Date

Social Security's Treatment of Postwar Americans: $\quad 9 / 99$

How Bad Can It Get?

Welfare, the Earned Income Tax Credit, and the

$9 / 99$

Labor Supply of Single Mothers

Short-Term Capital Flows

$9 / 99$

The Future of EMU: What Does the History of

$9 / 99$

Monetary Unions Tell Us?

Do Taxpayers Bunch at Kink Points?

$9 / 99$

The Effect of Marginal Tax Rates on Income: A Panel 9/99 Study of 'Bracket Creep'

What People Don't Know About Their Pensions

$9 / 99$

and Social Security: An Analysis Using Linked Data

From The Health and Retirement Study

Environmental Compliance Costs and Foreign Direct

$9 / 99$

Investment Inflows to U.S. States

Earnings Dynamics and Inequality among Canadian

$9 / 99$

Men, 1976-1992: Evidence from Longitudinal Income

Tax Records

Occupational Gender Composition and Wages in Canada: 9/99 1987-1988

The Adequacy of Life Insurance: Evidence from the

$10 / 99$ Health and Retirement Survey

Is Public R\&D a Complement or Substitute for Private $10 / 99$ R\&D? A Review of the Econometric Evidence

Do "High Performance" Work Practices Improve

$10 / 99$ Established-Level Outcomes?

You can download these and other papers at the NBER Web site:

www.nber.org

Free searchable abstracts are also available at the site. 
To order any of these papers in hard copy, see instructions at the end of this list. To subscribe to all NBER Working Papers or the papers in a single area, see instructions inside the back cover.

\begin{tabular}{|c|c|}
\hline Number & Author(s) \\
\hline 7375 & Charles I. Jones \\
\hline 7376 & $\begin{array}{l}\text { Harrison Hong } \\
\text { Jeremy C. Stein }\end{array}$ \\
\hline 7377 & $\begin{array}{l}\text { George Chacko } \\
\text { Luis M. Viceira }\end{array}$ \\
\hline 7378 & $\begin{array}{l}\text { Bruce A. Blonigen } \\
\text { Stephen E. Haynes }\end{array}$ \\
\hline 7379 & Victor R. Fuchs \\
\hline 7380 & $\begin{array}{l}\text { Michael D. Hurd } \\
\text { James P. Smith }\end{array}$ \\
\hline 7381 & Olivia S. Mitchell \\
\hline 7382 & $\begin{array}{l}\text { Michael B. Devereux } \\
\text { Charles Engel } \\
\text { Cedric Tille }\end{array}$ \\
\hline 7383 & $\begin{array}{l}\text { Stephen L. Mehay } \\
\text { Rosalie Liccardo Pacula }\end{array}$ \\
\hline 7384 & $\begin{array}{l}\text { Michael Klein } \\
\text { Giovanni Olivei }\end{array}$ \\
\hline 7385 & $\begin{array}{l}\text { Jean Abraham } \\
\text { Ashish Arora } \\
\text { Martin Gaynor } \\
\text { Douglas Wholey }\end{array}$ \\
\hline
\end{tabular}

$\underline{\text { Title }}$

$\underline{\text { Date }}$

Was an Industrial Revolution Inevitable?

$10 / 99$

Economic Growth Over the Very Long Run

Differences of Opinion, Rational Arbitrage

$10 / 99$ and Market Crashes

Dynamic Consumption and Portfolio Choice with

$10 / 99$

Stochastic Volatility in Incomplete Markets

Antidumping Investigators and the Pass-Through of

$10 / 99$

Exchange rates and Antidumping Duties

The Future of Health Economics

$10 / 99$

Anticipated and Actual Bequests

$10 / 99$

New Trends in Pension Benefit and

$10 / 99$

Retirement Provisions

Exchange Rate Pass-through and the Welfare

$10 / 99$

Effects of the Euro

The Effectiveness of Workplace Drug Prevention

$10 / 99$

Policies: Does 'Zero Tolerance' Work?

Capital Account Liberalization, Financial Depth and

$10 / 99$

Economic Growth

Enter at your own risk: HMO participation and

$10 / 99$

enrollment in the Medicare risk market

Copies of the above working papers can be obtained for $\$ 10.00$ per copy (plus $\$ 10.00$ per order for shipping for all locations outside the continental U.S.) to Working Papers, NBER, 1050 Massachusetts Avenue, Cambridge, MA 02138-5398. Pre-payment is required on all orders and may be made by check or credit card. Checks should be made payable to the NBER and must be in dollars drawn on a U.S. bank. If paying by credit card, include the cardholder's name, account number, and expiration date. For all orders, please be sure to include your return address and telephone number. Working papers may also be ordered by telephone (868-3900), fax (617-868-2742), or email (orders(a)nber.org).

You can download these and other papers at the NBER Web site:

\section{www.nber.org}

Free searchable abstracts are also available at the site. 